\title{
Trabalhar com famílias no Programa de Saúde da Família: a prática do enfermeiro em Maringá-Paraná*
}

\author{
WORKING WITH FAMILIES WITHIN THE FAMILY HEALTH PROGRAM: NURSE'S \\ PRACTICE IN MARINGÁ - PARANÁ
}

TRABAJAR CON FAMILIAS EN EL PROGRAMA DE SALUD DE LA FAMILIA: LA PRÁCTICA DEL ENFERMERO EN MARINGÁ - PARANÁ

Raquel Gusmão Oliveira', Sonia Silva Marcon²

\section{RESUMO}

O Programa de Saúde da Família (PSF) propõe-se a atender a família integralmente em seu espaço social o que requer uma nova postura profissional. Este estudo tem como objetivo conhecer a prática do trabalho realizado com famílias pelos enfermeiros que atuam no PSF em Maringá, Paraná. Foi realizado um estudo descritivo exploratório com abordagem qualitativa, utilizando, para a coleta de dados, entrevistas, observação e análise documental. Os dados foram analisados, segundo o referencial teórico de Bardin. Os resultados revelaram três categorias: atividades com indivíduos, atividades na comunidade e atividades no domicílio. Concluiu-se que, apesar de os enfermeiros considerarem a família em seu espaço domiciliar, por meio de visitas domiciliares, de coleta de dados e da educação em saúde, ainda centralizam a doença e o indivíduo, e a sua postura não tem estimulado a participação e a autonomia das famílias no que se refere à assistência e ao serviço.

\section{DESCRITORES}

Papel do profissional de enfermagem.

Saúde da Família.

Enfermagem familiar.

\section{ABSTRACT}

The Family Health Program (Programa de Saúde da Família, PSF) was conceived with the aim of fully assisting families in their social space, which requires a new professional posture. This work had the purpose of investigating the practices with families of the nurses that work in the PSF in the city of Maringá, in the State of Paraná. An exploratory descriptive study with qualitative approach was carried out using for data collecting interviews, observation and documental analysis. Data were analyzed according to Bardin theoretical referential. The results revealed three categories in the Nursing practice with families: activities with individuals, activities in the community and activities at family homes. It was concluded that in spite of the fact that nurses consider families in a home context through home visits, data collecting and health education, they still focus on the disease and on the individual. Such approach has not stimulated the participation and autonomy of the families regarding care and the service.

\section{KEY WORDS}

Nurse's role.

Family health.

Family nursing.

\section{RESUMEN}

El Programa de Salud de la Familia (PSF) se propone atender a la familia integralmente en su espacio social lo que requiere de una nueva postura profesional. En este trabajo se tuvo como objetivo conocer la práctica del trabajo realizado con familias por los enfermeros que actúan en el PSF en Maringá, Paraná. Se realizó un estudio descriptivo exploratorio con abordaje cualitativo, utilizando para la recolección de datos, entrevistas, observación y análisis documental. Los datos fueron analizados según el referencial teórico de Bardin. Los resultados revelaron tres categorías: actividades con individuos, actividades en la comunidad y actividades en el domicilio. Se concluye que a pesar de que los enfermeros consideran a la familia en su espacio domiciliario, por medio de visitas domiciliarias, de recolección de datos y de la educación en salud, aun centralizan la enfermedad y al individuo, y su postura no ha estimulado la participación y la autonomía de las familias en lo que se refiere a la asistencia y al servicio.

\section{DESCRIPTORES}

Rol de la enfermera.

Salud de la familia.

Enfermería de la família.

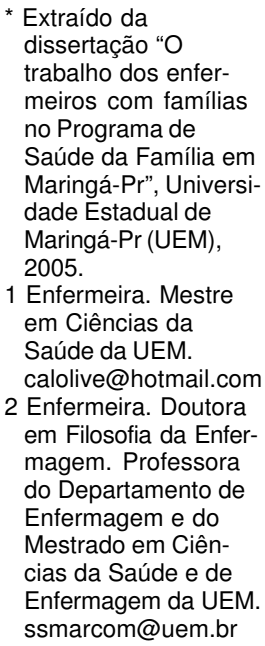

1 Enfermeira. Mestre em Ciências da Saúde da UEM. calolive@hotmail.com 2 Enfermeira. Doutora em Filosofia da Enfermagem. Professora do Departamento de Enfermagem e do Mestrado em Ciências da Saúde e de Enfermagem da UEM. ssmarcom@uem.br 


\section{INTRODUÇÃO}

O tema família vem sendo discutido durante décadas no setor saúde, tanto no cenário dos serviços como nas universidades. No contexto mundial essa discussão surgiu na década de 1960, e, no Brasil, no início de 1990, junto às discussões das políticas públicas, à reforma do Sistema Único de Saúde (SUS) e à divulgação do sucesso do modelo de saúde cubano, que é alicerçado no modelo de atenção primária à saúde com ênfase no médico da família. Em termos práticos, essas discussões deram impulso à implementação, inicialmente do Programa de Agentes Comunitários de Saúde (PACS) e, posteriormente, do Programa de Saúde da Família (PSF) ${ }^{(1)}$.

O PSF incorpora e reafirma os princípios básicos do SUS - universalização, descentralização, integralidade e participação da comunidade - e se alicerça sobre três grandes pilares: a família, o território e a responsabilização, além de ser respaldado pelo trabalho em equipe ${ }^{(2)}$.

Para o PSF, a família deve ser entendida de forma integral e em seu espaço social, ou seja, a pessoa deve ser abordada em seu contexto socioeconômico e cultural, e reconhecida como sujeito social portadora de autonomia, reconhecendo que é na família que ocorrem interações e conflitos que influenciam diretamente na saúde das pessoas. Em suma, o programa prevê que o profissional tenha compreensão de aspectos relacionados à dinâmica familiar, seu funcionamento, suas funções, desenvolvimento e características sociais, culturais, demográficas e epidemiológicas. Isso requer dos profissionais uma atitude diferenciada, pautada no respeito, na ética e no compromisso com as famílias pelas quais são responsáveis, mediante a criação de vínculo de confiança e de afeto, atuando de forma participativa na construção de ambientes mais saudáveis no espaço familiar ${ }^{(2)}$.

Neste novo modelo de assistência, o processo de trabalho deveria ganhar contornos específicos. O profissional deveria ter qualificação e perfil diferenciados, já que a ênfase da assistência não é nos procedimentos técnicos, mas sim na inter-relação equipe/comunidade/família e equipe/equipe ${ }^{(3)}$. No entanto, os treinamentos introdutórios propostos pelo Ministério da Saúde (MS) não contemplavam adequadamente a abordagem e o cuidado à família, pois discutiam aspectos como conceito, funções, papel na comunidade, influência no processo saúde-doença ${ }^{(4)}$, excluindo temas como estratégias e intervenção.

Preocupado com essa questão e na tentativa de melhor instrumentalizar e capacitar os profissionais da equipe para o trabalho com famílias, o MS, em parceira com o Instituto para o Desenvolvimento da Saúde (IDS), desenvolveu um material instrucional para educação à distância o qual foi disponibilizado on line e distribuído aos municípios com diversos temas específicos para cada profissional. O Manual de Enfermagem apresenta temas que focalizam abordagens e estratégias para assistir e compreender a família nos diferentes ciclos da vida ${ }^{(5)}$.

A preocupação do MS com esses aspectos é pertinente, pois uma das questões relacionadas ao PSF que vem sendo discutida no meio acadêmico é se o trabalho desenvolvido nesse programa, tem de fato, direcionado as suas ações para a família.

Pelo menos entre os enfermeiros, a preocupação em incluir a família sob o aspecto de objeto da assistência surgiu muito antes do propósito do PSF. Nessa área e mais especificamente na disciplina materno-infantil, a publicação sistemática de conhecimento acerca do tema família começou na década de 1980, dando início, e ainda em curso, a um lento processo de mudança no enfoque da assistência de enfermagem, que passou a incluir a família como objeto e parceira da assistência.

A produção científica tem apontado algumas características do que seria um trabalho com família, focalizando o mundo de suas interações, uma vez que são elas que sustentam e mantêm o núcleo familiar. Isso pressupõe que o profissional deve ter conhecimento dos conceitos de família, de saúde da família e de interação familiar $^{(6)}$.

Família é, antes de tudo, um corpo social em que prevalece a rede de relações e de interações, que possui crenças que são manifestadas em um espaço cultural, e a sua saúde deve ser entendida no contexto das relações entre seus membros, tanto sadios como doentes, visto a influência da saúde do indivíduo no grupo familiar e vice-versa ${ }^{(7)}$.

O objetivo da assistência é auxiliar a família a identificar e a sanar, se for possível, as suas perturbações interacionais, a enfrentar problemas e a tomar decisões. $\mathrm{O}$ foco do cuidado, portanto, deve estar em ajudar e em capacitar a família, de forma que ela possa atender às necessidades de seus membros, especialmente em relação ao processo saúde-doença, mobilizando recursos, promovendo apoio mútuo e crescimento ${ }^{(8)}$.

Para que um trabalho seja denominado de cuidado familiar, é necessário que o profissional tenha conhecimento acerca desse universo que é a família, pois cuidar implica na capacidade de entender e atender adequadamente as necessidades do outro. Nesses casos, não basta boa intenção, é necessária uma revisão de postura e inclusive reflexão sobre o conceito de conhecimento ${ }^{(9)}$, o qual não deve se restringir ao que é verbalizado. Por essa razão, para conhecer a família é preciso, além de saber ouvir, ser sensível o suficiente para enxergar nas entrelinhas e conhecer o que está implícito. 
Assim, para uma melhor interação com a família, os profissionais devem fazer uso de algumas estratégias como as visitas domiciliares, a educação em saúde (como prática de fortalecimento, participação e autonomia de indivíduos) e o acolhimento (escuta, compromisso, atenção, respeito), além do que, deve fazer uso de alguns instrumentos que permitam o reconhecimento das características da família como um todo, tais como o genograma e o ecomapa, dentre outros $^{(5-12)}$.

Outro aspecto apontado com freqüência está relacionado à postura do profissional diante da família. Para alguns, ela tem sido colocada em termos de estar com a família ${ }^{(12)}$, para oferecer apoio e suporte, seja em situações de saúde como de doença, envolvendo respeito à cultura, conhecimentos e práticas da família; para outros, é definida a partir da concepção da família sob o aspecto de co-participante do processo de cuidar $^{(8)}$.

Ao adotar essa concepção o profissional, além de assegurar a participação da família na definição e no planejamento da assistência, passa a atuar com vistas a instrumentalizá-la para tomar decisões relacionadas com a saúde e com a doença de seus membros. Isso envolve informar, discutir, compartilhar e negociar com a família os aspectos diagnosticados que interferem em seu processo de ser/estar saudável, bem como ações e estratégias que podem contribuir para reverter, quando necessário ou quando possível, a situação encontrada ${ }^{(8)}$.

Vale ressaltar que, embora seja desejável conhecer o ambiente da família para melhor compreender as suas crenças, as suas práticas e seus valores sobre saúde e doença, e também as suas reais necessidades de cuidado, assistir a família é possível em qualquer ambiente, pois o fator delimitador de águas nessa assistência é a postura profissional que se assume diante da família. Assim, considerando que um dos alicerces do trabalho do PSF é a família e que os seus propósitos não são contraditórios aos que têm sido identificados na literatura de enfermagem sobre um trabalho com família, bem como a nossa preocupação com o trabalho do enfermeiro no contexto do PSF, propusemo-nos a desenvolver o presente estudo, cuja questão norteadora foi: Como é a prática do trabalho do enfermeiro com famílias no Programa de Saúde da Família de Maringá - PR?

Para responder esse questionamento, formulamos os seguintes objetivos:

- identificar o conceito de família que o enfermeiro utiliza em sua prática de trabalho; e

- identificar as atividades desenvolvidas pelo enfermeiro que são voltadas para família.

\section{MÉTODO}

Este artigo trata-se de um estudo descritivo-exploratório com abordagem qualitativa, realizado em Maringá, Paraná, junto a 20 enfermeiros atuantes nas equipes do PSF do município.

O PSF foi implantado no município de Maringá em 1999, inicialmente com 07 equipes. Na época do estudo, já existiam 62 equipes, distribuídas nas 23 unidades básicas de saúde (20 na zona urbana, 2 nos distritos e 1 na zona rural) pertencentes a 5 regionais de saúde, que atendiam 69.960 famílias, significando uma cobertura populacional de $81 \%$.

Com a intenção de ter um informante por unidade na zona urbana, foi selecionado aleatoriamente um enfermeiro de cada UBS, não levando em consideração o número de equipes de PSF ali alocados. A coleta de dados foi realizada no período de fevereiro a agosto de 2004, por meio de três diferentes técnicas: entrevistas semi-estruturadas (gravadas), observação de visitas domiciliares e análise de prontuários. Para cada uma dessas técnicas foram utilizados instrumentos específicos, elaborado pelas autoras e submetidos à avaliação de conteúdo por quatro peritos.

As entrevistas, previamente agendadas por telefone, foram realizadas com o uso de um roteiro constituído de duas partes: a primeira com questões objetivas relacionadas à identificação das características sócio-demográficas; e a segunda constituída de oito questões abertas sobre o conceito de família e de saúde da família e da prática do trabalho com famílias, que incluía citação e descrição das atividades realizadas e das técnicas e dos instrumentos conhecidos e utilizados.

Após o término das entrevistas e de uma pré-análise, os 20 enfermeiros (enf) foram separados em 2 grupos, segundo a frequiência de realização das visitas domiciliares. $\mathrm{O}$ grupo 1 foi composto por 11 enfermeiros que realizavam visitas domiciliares uma vez por semana, quando tinham disponível o transporte da Secretaria de Saúde; o grupo 2, por 9 enfermeiros que realizavam visitas mais de uma vez por semana, independente da disponibilidade do transporte. De cada grupo foi selecionado, por conveniência, um enfermeiro para ser acompanhado e observado durante a realização de visitas domiciliares. Para essa observação foi utilizado um roteiro constituído de dados de identificação das visitas e dados da observação propriamente dita: forma de coleta de dados e abordagem da família, atividades realizadas e orientações prestadas. Também foi observada a postura do enfermeiro diante da família.

Em seguida, objetivando coletar informações acerca das anotações do enfermeiro relacionadas às suas abordagens e atendimento, foi feita consulta aos prontuários dos pacientes visitados durante a observação. O roteiro utilizado focalizava a presença do registro das visitas domiciliares, bem como a qualidade e o conteúdo desses registros, de modo a identificar nos registros ações voltadas às famílias. 
Para a análise e a interpretação dos dados das entrevistas, utilizou-se da análise de conteúdo ${ }^{(13)}$. Após a transcrição das fitas, o material foi lido na íntegra, iniciando a pré-análise e a exploração dos dados; em seguida foram organizados sistematicamente e agregados em unidades, permitindo uma descrição exata das características pertinentes.

Procedeu-se, então, a categorização, que consistiu em isolar os elementos do discurso e impor certa organização às mensagens, investigando o que cada um tem em comum com o outro (atividades com indivíduos, atividades na comunidade e atividades no domicílio), ou então isolando-os segundo os temas propostos previamente (conceito de família e atividades realizadas). Em seguida, foi realizada inferência, ou seja, a partir dos dados obtidos e utilizando como referencial teórico o material disponível acerca do PSF e publicações científicas acerca do trabalho com famílias, buscou-se levantar conclusões sobre as características do trabalho com família no PSF.

O estudo obedeceu aos preceitos éticos de pesquisa com seres humanos disciplinados pela Resolução 196/96, sendo aprovado pelo Comitê de Ética da Universidade Estadual de Maringá (Parecer 159/2003).

\section{RESULTADOS}

\section{Os enfermeiros e o conceito de família}

A despeito de toda a complexidade que envolve a família, é necessário que o profissional ou a equipe que trabalha com ela, para fins operacionais e de comunicação, tenha uma definição própria de família, pois isso indica, de certo modo, até onde vai o olhar e a intenção em se trabalhar com as famílias, influenciando o comportamento do profissional, fortalecendo ou estimulando dependência e, ainda, se trabalha com o todo ou com as partes ${ }^{(12)}$.

O conceito de família para os enfermeiros em estudo ressalta o aspecto social, visto que prioriza o viver junto, como característica $^{(14)}$.

É o conjunto de pessoas que convivem no mesmo local, debaixo do mesmo teto, com ou sem laço de consangüinidade. (enf. 19)

...eu acho que família é algumas pessoas que moram numa casa, que dividem os problemas, suas dores, suas alegrias (enf. 3)

A ênfase nesse aspecto pode ser atribuída ao conceito de família proposto no PSF, o qual elegeu o espaço domiciliar como foco de sua atenção. Contudo, as publicações do MS enfatizam que esse ambiente não deve ser percebido apenas como uma delimitação geográfica, mas sim como um espaço onde se constroem as relações intra e extradomiciliares, onde se desenvolve a luta pela melhoria das condições de vida e onde é possível uma compreensão mais ampliada do processo saúde/doença ${ }^{(15)}$.
A família também é percebida como provedora de cuidado:

É um ajudando o outro, é cumplicidade, amor, carinho, amizade, companheirismo... (enf. 3)

Família é aquele que cuida, é um cuidando do outro...(enf. 11)

O cuidado familiar é caracterizado por ações e por interações presentes no núcleo familiar direcionado a cada um de seus membros, com o intuito de alimentar e fortalecer o seu crescimento, o seu desenvolvimento, a sua saúde e seu bemestar; ele pode ser reconhecido por meio de inúmeros atributos, dentre os quais se destacam: a presença, a proteção, a inclusão, a orientação e a formação ${ }^{(14)}$.

Cabe destacar que ao expressarem a dificuldade em definir família, alguns enfermeiros revelaram ciência das alterações nos arranjos familiares ocorridas nos últimos anos em decorrência das mudanças sociais nos diferentes grupos ou classes. Para outros essa dificuldade pode ser justificada, em parte, pela ausência de um arcabouço teórico prático que sustente as ações das equipes para trabalhar na proposta do $\operatorname{PSF}^{(16)}$.

Hoje em dia é muito complicado você falar do que é uma família. Hoje tem vários tipos de família, várias organizações de famílias... (enf. 9)

Hoje em dia é difícil dizer o que é família... (enf. 12).

\section{O trabalho do enfermeiro com familias}

$\mathrm{Na}$ análise dos dados, pudemos identificar três categorias de atividades relativas ao trabalho do enfermeiro com famílias: a) atividades para indivíduos, b) atividades na comunidade e c) atividades no domicílio.

\section{a) Atividades para indivíduos}

Apesar do propósito do PSF de focalizar a família em seu processo de trabalho, chamou-nos atenção o fato de vários enfermeiros reconhecerem que não desenvolvem atividades com famílias:

Estamos voltados para indivíduos, e não para a família (enf. 3)

Eu trabalho com o doente, e não com a família... (enf. 9)

É interessante observar que, apesar de alguns enfermeiros reconhecerem que não trabalham com famílias, eles referiram realizar atividades com grupos e visitas domiciliares, o que para outros enfermeiros foi interpretado como sendo um trabalho com famílias. Isso revela que esses percebem que o trabalho com famílias é muito mais complexo do que a mera realização de atividades no domicílio, o que quase sempre é realizado de forma individual e curativa.

... a gente tenta consultar e fazer o que pode pra todo mundo daquela família, pra diminuir a demanda da unidade, pede exames, entrega remédios... (enf. 13) 


\section{b) Atividades na comunidade}

Nas atividades com/na comunidade, estão os grupos de patologias específicas e os grupos do ciclo vital.

A gente tem grupos de hipertenso, diabético. Os grupos são específicos mas não se restringe, às vezes tem a família junto, a gente orienta... (enf. 19)

A gente faz grupos de idosos, hipertenso, diabéticos e artesanato, mas para família especificamente, envolvendo todos os membros a gente não faz... (enf. 9)

O programa enfatiza ações de assistência integral em todas as fases do ciclo de vida - da criança, do adolescente, da mulher, do adulto e do idoso - e em diferentes ambientes, cabendo ao enfermeiro organizar e coordenar a criação de grupos de patologias específicas ${ }^{(2)}$. Em alguns momentos, as atividades desses grupos são realizadas fora do ambiente das unidades, mais perto do indivíduo, conforme afirmam os enfermeiros (salão da igreja, centros comunitários dos bairros, parques, praças e quadras, domicílios, creches, escolas e casa do PSF). Isso possibilita que o enfermeiro, acostumado com o trabalho dentro das unidades de saúde, ao se ver envolvido em atividades fora das unidades e mais próximo da população e de seu ambiente familiar considere tais atividades como sendo trabalhar com famílias.

Sem dúvida, os momentos de mudança do ciclo vital e de aparecimento de doenças crônicas são situações que podem permitir ao profissional criar vínculo com o paciente $\mathrm{e}$ sua família mais naturalmente. A atenção dada pelo profissional nesses momentos pode facilitar sua aceitação e intervenção, mas trabalhar com famílias é diferente de trabalhar com indivíduos ou com grupos.

\section{c) Atividades no domicílio}

Na categoria de atividades no domicílio, a ênfase recai sobre a coleta de dados, a educação em saúde e as visitas domiciliares. A coleta de dados tem sido restringida ao cadastramento das famílias no programa, mais especificamente por meio do preenchimento da ficha A, que contempla dados referentes à identificação dos membros da família (nome, idade, escolaridade, ocupação, sexo, doença referida) e das condições de vida das famílias (situação de moradia e saneamento e informações a respeito de plano e saúde, de meios de comunicação e de transporte utilizados, da participação em grupos comunitários e da procura de serviços de saúde). Esses dados alimentam o banco de dados do Sistema de Atenção Básica (SIAB).

A gente está tentando fazer um cadastro familiar mais específico... para ter uma visão mais aprofundada da família... (enf. 19)

A gente acaba conhecendo a família porque o ACS traz informação de tudo, ..., a gente acaba conhecendo a família através disso. (enf. 1)
O que a gente está fazendo é o recadastramento dessas famílias. O cadastramento havia sido feito há mais de dois anos atrás, com isso estamos visitando os pacientes. (enf. 13)

O que nos chama a atenção é que poucos enfermeiros afirmam conhecer outras técnicas ou instrumentos para coletar dados das famílias, além da ficha A. A utilização de instrumentos específicos é fundamental para a coleta apropriada de dados, possibilitando a avaliação das necessidades e das potencialidades da família, facilitando a organização dos dados e direcionando o foco da intervenção.

O genograma (que detalha a estrutura e o histórico familiar nas diferentes gerações) e o ecomapa (diagrama das relações entre a família e a comunidade) são exemplos de instrumentos que auxiliam na avaliação da família. São simples de serem usados, permitem uma rápida visão da complexidade das relações familiares e funcionam como uma rica fonte de informações para o planejamento e definição de estratégias $^{(17-18)}$, mas esses não foram citados por nenhum dos enfermeiros como instrumento para o trabalho com famílias.

Ao observarmos os registros efetuados nos prontuários dos indivíduos/famílias visitados pelos enfermeiros, além de confirmarmos a não-utilização de instrumentos específicos para a coleta de dados da família, também identificamos que a qualidade e a quantidade de informações são escassas, de caráter individual e se restringem aos aspectos da doença e aos procedimentos realizados nas unidades. Não há registros da história de vida pessoal e familiar. Os registros das visitas se resumem a frases simplificadas, como: realizada visita domiciliar, feitas orientações, entregue medicamentos, verificado pressão arterial.

Observamos também que a coleta de dados da família é feita em situações bem específicas (no caso de esclarecimento de alguma dúvida, sobre quem cuida do paciente, contatos em caso de doença contagiosa) e de maneira nãosistematizada, e que esses aspectos sequer são registrados no prontuário.

A educação em saúde, quando realizada de forma dialogada e participativa entre diferentes saberes, com intuito de ajudar as pessoas na compreensão das raízes de seus problemas e na busca de soluções compartilhadas para melhoria da qualidade de vida de indivíduos, de grupos e de populações, constitui um importante instrumento para o trabalho com famílias ${ }^{(10)}$. No entanto, verificou-se que a concepção de educação em saúde dos enfermeiros é a tradicional, em que o repasse do saber acontece verticalmente, junto a um usuário passivo que deve modificar seu comportamento de acordo com o que é recomendado.

Ah, a gente conversa com a família, a médica fala o que a pessoa tem, o provável diagnóstico, a gente orienta, explica; daí tem os medicamentos, a gente orienta como é que é para tomar, se for outro cuidado a gente envolve, a 
gente fala o que tem que fazer, assim para melhorar, alimentação ou os medicamentos no horário correto, e quando é curativo assim simplezinho, a gente orienta como eles podem fazer, a gente sempre está à disposição daquela família, se tiver dúvida e não for o dia da visita, chega até a unidade, conversa. (enf. 11)

Em decorrência disso, o conteúdo das orientações segundo referem os enfermeiros, são de caráter essencialmente curativo, baseado em comportamento adequado, e relacionado ao uso correto da medicação, ao controle de hipertensão e de diabetes e a observância de dietas, esclarecimento da patologia ou ainda sobre as atividades da UBS, dentre outros. Na observação das visitas, além de confirmar esses dados, pudemos perceber que as orientações são sempre dirigidas ao paciente ou ao cuidador e de forma verticalizada, não valorizando a participação e a troca de saberes.

Vale ressaltar que em suas diretrizes o PSF orienta a participação comunitária e o controle social, como estratégia para o alcance dos princípios do SUS, cabendo à enfermeira criar condições e estimular a participação dos usuários nos processos educativos, assim como no planejamento e na avaliação da assistência.

A visita domiciliar(VD) tem sido um instrumento utilizado pela enfermagem em Saúde Pública há anos tendo sofrido forte influência do modelo de Atenção Primária a Saúde (APS), no que se refere ao seu caráter preventivo; mas se descaracterizou com a valorização do espaço hospitalar ${ }^{(19)}$. Apesar da reorganização de unidades de saúde para a produção das ações preventivas e de promoção a saúde, advindas da implantação do SUS, as VDs só ganharam maior destaque a partir da implantação do PACS e do PSF. É importante destacar que a visita domiciliar só se configura como instrumento de intervenção quando planejada e sistematizada, de outra forma configura-se como mera atividade social ${ }^{(19)}$.

A forma como ocorre o planejamento das visitas, segundo as respostas dos enfermeiros, varia de acordo com as equipes/enfermeiros, mas, em sua maioria, é feito em reuniões semanais da equipe. A condição de saúde e de cuidado dos pacientes da área de abrangência da equipe é apresentada pelos ACS. Após discussão dos casos, os pacientes a serem visitados são selecionados conforme a prioridade, ou seja, a gravidade da doença ou estado do paciente.

O depoimento a seguir apresenta detalhes de como é feito o planejamento de uma visita:

Nas visitas, é realizado um levantamento, um diagnóstico da família, levantando todos os problemas sociais, econômicos, psicológicos da pessoa, higiene. Coletamos toda a história da família, faz toda aquela observação, coisas que a gente não pergunta, mas vai observando, estrutura da casa, higiene. Depois é discutida com o médico e a equipe toda, depois do levantamento de problemas, vem a intervenção, a gente faz as visitas e vai realizando as intervenções tanto de enfermagem quanto às médicas. Tudo é previamente planejado, tanto no domicilio quanto na unidade. (enf. 18)

Nesse discurso, a enfermeira revela que a equipe possui conhecimento a respeito de planejamento e, ao mesmo tempo, demonstra que ela própria tem domínio do instrumento visita domiciliar - ao citar as suas etapas (coleta de dados, identificação de problemas, intervenção) e relacionar o objetivo da VD com a resolução de problemas previamente levantados, e não apenas os imediatos. No entanto, os depoimentos dos enfermeiros demonstram que essa não é a realidade vivenciada pela maioria das equipes de PSF em estudo. Além disso, embora não tenha sido possível observar nenhuma reunião da equipe para planejamento de atividades, com a observação das VD foi possível constatar que o ACS é mesmo o ponto de ligação entre a equipe e a comunidade, visto ser sempre ele quem estabelece o itinerário e indica o melhor caminho para a localização das residências.

Quanto à frequiência das visitas, os depoimentos revelaram que em algumas equipes elas são feitas apenas quando o veículo da Secretaria Municipal de Saúde está disponível para equipe, o que ocorre uma vez por semana na forma de escala (dia e período previamente agendado). E em outras equipes as visitas são mais freqüentes, pois são realizadas no dia de disponibilidade do veículo da Secretaria, e também, em outros dias, quando são feitas a pé ou com veículo próprio.

Durante as sessões de observação, pudemos constatar que a freqüência está relacionada com a distância entre a UBS e a área de abrangência da equipe. Isso ocorre porque algumas UBS têm alocado em sua infra-estrutura várias equipes de PSF. Assim, se a área de abrangência fica distante da UBS, as visitas só são realizadas quando o veículo é disponibilizado para aquela equipe (uma vez por semana).

A frequiência das visitas parece interferir na qualidade do relacionamento entre enfermeiro e/ou equipe de saúde com a família e/ou paciente. Ao acompanharmos a enfermeira nas visitas domiciliares realizadas a pé, foi possível observar que ela é bem conhecida pela população, as pessoas a cumprimentam na rua e param para conversar, dando a impressão de ter mais liberdade, o que nos induz a pensar que o vínculo entre elas é maior.

A importância de se considerar a família no contexto domiciliar é porque esse espaço permite uma compreensão mais ampliada do processo saúde/doença. No entanto o objetivo e as atividades realizadas durante as visitas, segundo afirmam os enfermeiros e pela observação realizada, têm sido intervir na doença do indivíduo, demonstrando que muitas vezes, a VD não tem auxiliado nessa compreensão mais ampliada do processo saúde-doença.

\footnotetext{
... é a consulta médica, os pacientes que a gente visita são pacientes que precisam de uma consulta e não tem condições de vir ao posto... (enf. 1)
}

Trabalhar com famílias no Programa de Saúde da Família: a prática do enfermeiro em Maringá-Paraná Oliveira RG, Marcon SS. 
... é apagar fogo... (enf. 15)

... é curativo, o médico vai na casa atender o paciente que está passando mal. (enf. 17)

Durante as visitas, os depoimentos puderam ser confirmados, pois das 24 visitas acompanhadas, 12 foram para atendimento de queixas de doenças, 5 para realização de curativos, 5 para orientações de exames e medicação e apenas 2 foram para acompanhamento do puerpério. Vale ressaltar que o contato inicial com essas famílias, segundo os enfermeiros, também foram em sua maioria por motivo de doença crônica ou aguda na família.

Apesar de o PSF focalizar a família, a prática dos enfermeiros ser centrada nas visitas domiciliares, parece que esta vem sendo mais uma atividade entre as muitas que os enfermeiros devem realizar. Vale ressaltar que as características do modelo assistencial (biologicista e funcionalista) vigente visam à resolução imediata das queixas, tornando a visita domiciliar uma prática simplificada de assistência ${ }^{(20)}$.

As atividades realizadas durante as visitas, na maior parte das vezes, possuem caráter essencialmente curativo e individual, segundo as respostas dos próprios enfermeiros, e limitam-se a procedimentos de enfermagem como: curativos, medicação, verificação de sinais vitais. Isso também foi percebido durante as observações, em que a abordagem é feita sempre ao indivíduo com queixa de doença, ou que necessita de exames ou procedimentos curativos. A relação com a família se restringe ao cuidador, o qual, quando presente, recebia informações e orientações acerca do cuidado a ser realizado ao indivíduo doente.

No que se refere à relação do enfermeiro com a família, apesar desta ser reconhecida como provedora de cuidados, não tem sido incluída no planejamento e nas decisões relacionadas à assistência, sendo vista como mera receptora passiva dos cuidados e de informações prestados. Isso também foi confirmado durante a observação. A equipe e de forma particular, o enfermeiro não aproveitaram a oportunidade das VDs para intervirem no contexto familiar e nem tampouco na família, de forma a explorarem as relações entre os membros, a dinâmica da família, identificarem quem toma as decisões, nem demonstraram interesse por todo os membros, em especial por aqueles que estavam com saúde no momento em que foi realizada a visita.

Cabe destacar que isso realmente se torna muito difícil, pois, conforme pudemos observar, em uma mesma tarde foram realizadas de seis a oito visitas. Em tais condições, fica difícil para a equipe estabelecer vínculos e conhecer de fato as famílias: condição indispensável para um trabalho com famílias.

Em relação à postura dos enfermeiros, o que observamos nos permite concluir que o acolhimento, sob o aspecto de instrumento e tecnologia, ainda não é utilizado adequadamente. Apesar de o enfermeiro ser cordial, ter sido bem recebido, ter respeito e ter dado atenção às pessoas, o conceito vai muito além, é produto da relação de trabalhadores de saúde e usuários, entendido com novos valores de solidariedade e responsabilidade social, compromisso e construção da cidadania e de uma nova ética. Em última instância, significa permitir que o usuário se organize como sujeito, animando-o a recorrer ao serviço ${ }^{(9)}$.

Ao analisarmos publicações acerca do trabalho do enfermeiro no PSF em outros municípios ${ }^{(21-22)}$, verificamos que os autores afirmam que esse profissional centra a sua atenção na família e atua junto a ela. No entanto, ao buscarmos as descrições das atividades realizadas, não é possível perceber essa centralidade. Um exemplo dessa distorção é a referência às VDs como uma das principais formas de abordagem da família, entretanto os próprios autores referem que esta ocorre em casos em que os pacientes (indivíduos) necessitam de procedimentos especiais.

Na prática, muitas vezes os enfermeiros acreditam estar cuidando da família mesmo quando o seu processo de trabalho não se diferencia daquele adotado na assistência ao indivíduo, levando-nos a considerar que o que está acontecendo é assistência ao indivíduo que tem família, e não a assistência à família ${ }^{(23)}$.

Apesar de os enfermeiros estarem inseridos no PSF, que tem como um dos pressupostos focalizar a família, a assistência de enfermagem e os serviços de saúde são marcados historicamente pela atenção individual, biologicista, curativa e hospitalocêntrica. Além disso, algumas críticas ao programa ressaltam que a sua implantação significou muito mais uma nova divisão do trabalho, deslocamento de atuação e acréscimo da remuneração da equipe, do que uma maior aproximação com o cotidiano das famílias ${ }^{(1)}$.

Isso caracteriza o cuidado da saúde da família como prática tradicional de abordagem individual ou de relação com grupos comunitários, considera qualquer intervenção da equipe como familiar e faz com que o termo família perca a sua especificidade, também dificulta o alcance da integralidade e do cuidado, produz dificuldades de entendimento no planejamento, no cuidado, na orientação para a formação profissional, além de frustrações pelas expectativas não atendidas ${ }^{(24)}$.

Aos profissionais cabe a iniciativa de buscarem conhecimento e instrumentos para o trabalho com famílias. Em relação ao PSF, vale ressaltar que é necessário reconsiderar metas e promover reajustes na prática acerca do trabalho com famílias, considerando que os princípios e diretrizes do programa, por si só, são incapazes de responder ao propósito de inversão do modelo assistencial, exigindo ações muito mais abrangentes (ligadas ao meio, à economia, à política agrária, à assistência social, à educação e ao lazer) do que a capacidade de intervenção das equipes de saúde da família ${ }^{(25)}$.

\section{CONSIDERAÇÕES FINAIS}

É possível observar que os pressupostos teóricos do PSF e o contexto de trabalho do enfermeiro favorecem a interação 
com a família, e atividades como as visitas domiciliares, a coleta de dados e os momentos de orientações são situações oportunas para o enfermeiro trabalhar com a família e cumprir as atividades preconizadas pelo PSF. No entanto, parece que há um certo despreparo do enfermeiro para assistir a família, visto que a utilização de estratégias como a VD, a educação em saúde e o acolhimento ainda são marcados pelo modelo tradicional, curativo e individual da assistência.

$\mathrm{O}$ atendimento ao indivíduo no ambiente familiar tem sido considerado, pelos enfermeiros em estudo, como um trabalho com famílias, com predomínio das atividades de caráter curativo centrado na doença e no indivíduo, restringindo a relação com a família aos momentos de orientações ao cuidador acerca do cuidado a ser realizado ao indivíduo.

\section{REFERÊNCIAIS}

1. Vasconcelos EM. A priorização da família nas políticas públicas de saúde. Saúde Deb. 1999;23(53):6-19.

2. Brasil. Ministério da Saúde. Secretaria de Políticas Públicas. Guia prático do Programa de Saúde da Família. Brasília; 2001.

3. Cruz MGB. Estudo comparativo de alguns indicadores em municípios do Estado de São Paulo segundo a implantação do saúde da família. Rev Esc Enferm USP. 2005;39(1):28-35.

4. Brasil. Ministério da Saúde. Secretaria de Políticas Públicas. Treinamento introdutório. Brasília; 2000.

5. Brasil. Instituto de Desenvolvimento da Saúde. Universidade de São Paulo. Ministério da Saúde. Manual de enfermagem. Brasília; 2001.

6. Elsen I. Desafios da enfermagem no cuidado da família. In: Bub LIR, organizador. Marcos para a prática de enfermagem com famílias. Florianópolis: Ed. da UFSC; 1994. p. 61-77.

7. Elsen I, Marcon SS, Silva MRS, organizadoras. O viver em família e sua interface com a saúde e a doença. $2^{a}$ ed. Maringá: Eduem; 2004.

8. Marcon SS, Radovanovic CAT, Waidman MAP, Oliveira MLF, Sales CA. Vivência e reflexão de um grupo de estudos junto às famílias que enfrentam a situação crônica de saúde. Texto Contexto Enferm. 2005;14(n. esp.):116-24.

9. Kakehashi TY, Silva CV. O cuidar da criança e da família: das reflexões teóricas a sua aplicação na prática profissional do cotidiano. Fam Saúde Desenv. 2001;3(1):15-20.

10. Wendhausen A, Saupe R. Concepções de educação em saúde e a estratégia de saúde da família. Texto Contexto Enferm. 2003;12(1):17-25.

11. Gaíva MM. A família como foco de cuidado em enfermagem. Coletânea Enferm. 1999;1(2):9-20.

12. Angelo M. Com a família em tempos difíceis: uma perspectiva de enfermagem [tese]. São Paulo: Escola de Enfermagem, Universidade de São Paulo; 1997.

13. Bardin L. Análise de conteúdo. Lisboa: Edições 70; 1977.

14. Petrini JC. Pós-modernidade e família: um cenário de compreensão. Bauru: EDUSC; 2003.
Revela assim, que a prática do trabalho com famílias realizado pelos enfermeiros no contexto do Programa de Saúde da Família no município de Maringá, Paraná, tem muito que avançar no que se refere ao conhecimento dos profissionais acerca da família, da saúde da família e de instrumentos para a interação familiar e na estruturação do PSF propriamente dita. Muitas vezes, os enfermeiros acreditam estar cuidando da família mesmo quando o seu processo de trabalho não se diferencia daquele adotado na assistência ao indivíduo, levando-nos a considerar que o que está acontecendo é assistência ao indivíduo que tem familiares e não a assistência à família sob o aspecto de unidade de cuidado.

15. Brasil. Ministério da Saúde. Secretaria de Políticas de Saúde. Saúde da Família: uma estratégia para a reorientação do modelo assistencial. Brasília; 1997.

16. Wagner HL, Wagner ABP, Oliveira E, Talbot Y. Trabalhando com famílias em saúde da família [texto na Internet]. [citado 2003 jan. 12]. Disponível em: <http://www.sobral.ce.gov.br/ saúde da família>

17. Bousso RS, Ângelo M. A enfermagem e o cuidado na saúde da família. In: Brasil. Instituto de Desenvolvimento da Saúde. Universidade de São Paulo. Ministério da Saúde. Manual de enfermagem. Brasília; 2001. p. 18-22.

18. Wright L, Leahey M. Enfermeiras e família: um guia para avaliação e intervenção na família. São Paulo: Roca; 2002.

19. Egry EY, Fonseca RMGS. A família, a visita domiciliária e a enfermagem: revisitando o processo de trabalho da enfermagem em saúde coletiva. Rev Esc Enferm USP. 2000;34(3):233-9.

20. Takahashi RF, Oliveira MAC. A visita domiciliária no contexto da saúde da família. In: Brasil. Instituto de Desenvolvimento da Saúde. Universidade de São Paulo. Ministério da Saúde. Manual de enfermagem. Brasília; 2001. p. 43-6.

21. Costa MBS, Lima CB, Oliveira CP. Atuação do enfermeiro no Programa Saúde da Família (PSF) no Estado da Paraíba. Rev Bras Enferm. 2000;53(n. esp.):149-52.

22. Costa ARC, Melo MC, Oliveira MA, Dias RN. Atuação do enfermeiro no Programa de Saúde da Família em Sobradinho II. Rev Bras Enferm. 2000;53(n. esp.):127-30.

23. Marcon SS, Elsen I. A enfermagem com um novo olhar... a necessidade de enxergar a família. Fam Saúde Desenv. 1999; 1(1/2):21-6.

24. Ribeiro EM. As várias abordagens da família no cenário do programa/estratégia de saúde da família (PSF). Rev Lat Am Enferm. 2004;12(4):658-64.

25. Antunes MJM, Egry EY. O Programa de Saúde da Família e a reconstrução da atenção básica no SUS: A contribuição da enfermagem brasileira. Rev Bras Enferm. 2001;54(1):98-107. 